\title{
Frequency Effects on the Stability of a Journal Bearing for Periodic Loading
}

D. Vijayaraghavan

Lewis Research Center

Cleveland, Ohio

and

D.E. Brewe

Propulsion Directorate

U.S. Army Aviation Systems Command

Lewis Research Center

Cleveland, Ohio

Prepared for the

STLE-ASME Joint Tribology Conference

St. Louis, Missouri, October 13-16, 1991 


\title{
FREQUENCY EFFECTS ON THE STABILITY OF A JOURNAL BEARING FOR PERIODIC LOADING
}

\author{
D. Vijayaraghavan* \\ National Aeronautics and Space Administration \\ Lewis Research Center \\ Cleveland, Ohio 44135 \\ D.E. Brewe \\ Propulsion Directorate \\ U.S. Army Aviation Systems Command \\ Lewis Research Center \\ Cleveland, Ohio 44135
}

\section{Summary}

In this paper, stability of a journal bearing is numerically predicted when an unidirectional periodic external load is applied. The analysis is performed using a cavitation algorithm, which mimics the JFO theory by accounting for the mass balance through the complete bearing. Hence, the history of the film is taken into consideration. The loading pattern is taken to be sinusoidal and the frequency of the load cycle is varied. The results are compared with the predictions using Reynolds boundary conditions for both film rupture and reformation. With such comparisons, the need for accurately predicting the cavitation regions for complex loading patterns is clearly demonstrated. For a particular frequency of loading, the effects of mass, amplitude of load variation and frequency of journal speed are also investigated. The journal trajectories, transient variations in fluid film forces, net surface velocity and minimum film thickness and pressure profiles are also presented.

\section{Introduction}

In order to effectively analyze the performance of a bearing for various industrial applications, a transient analysis is required. However, the analysis of dynamically loaded bearings are usually performed for known/predicted journal trajectories or by using linearized theory to predict the whirl. The stability of the system under a known journal trajectory can not be determined since the equations of motion are not considered. The linearized theory assumes the equilibrium position as the starting point. By perturbing the journal center a small amount from equilibrium, the stiffness and damping coefficients, critical mass and the whirl ratio are determined. The critical mass is important since it is a measure of stability. The nonlinear film forces are linearized for the motion to be analytically tractable. The linearized theory can predict the threshold of stability but not postwhirl orbit details. On the other hand, nonlinear transient analysis does not attempt to linearize the equations of journal motion and hence determines the locus of the journal for the operating conditions. The stability of the system can be determined from the journal locus.

Holmes (1960), in an analysis of the vibration of a rigid shaft for short sleeve bearings, determined that the occurance of whirl is a function of steady state eccentricity, angular frequency and clearance. The plot of the "whirl boundary" was based on the short bearing approximation and the Gümbel boundary conditions. Mitchell, Holmes and Byrne (1965) used nonlinear theory with short/long bearing approximations to determine the characteristics of oil whirl of a full journal

*National Research Council-NASA Research Associate at Lewis Research Center. 
bearing with the aid of analog and digital computation as well as experimental data. Capriz (communications on Mitchell et al; 1965) considered cavitation along with the nonlinear motion and presented a stability diagram. However, the relative movement of the cavity to the minimum film thickness was not determined and the cavity was assumed to rotate at the whirl frequency. Jakobsen and Christensen (1968) analyzed nonlinear transient vibrations under a constant external load and presented the journal loci for various journal masses and starting positions. Akers, Michaelson and Cameron (1971) extended the work of Holmes (1960) and Capriz (1965) for finite bearings and determined the journal trajectories for both cavitated and uncavitated bearings and for various L/D ratios. The out of balance load and friction force were also considered in the analysis. Kirk and Gunter (1970) used a short bearing approximation in a transient analysis of journal bearings. Badgley and Booker (1969) analyzed the effect of initial transients on turborotor stability. Short bearing (Ocvirk), long bearing (Sommerfeld) and finite bearing (Warner) approximations were used to model the film and the film was assumed to extend $180^{\circ}$ between variable limits. The rest of the bearing was taken to be cavitating at zero pressure. Allaire (1979) presented the stability analysis of finite journal bearings using linearized theory. Majumdar and Brewe (1987) analyzed the stability of a rigid rotor supported on a journal bearing, under unidirectional constant, periodic and variable load patterns. The analysis included nonlinear motion but only Reynolds boundary conditions were used for film rupture and reformation. It has been clearly brought out in the above mentioned papers that while linearized theory can predict the threshold of stability due to small perturbations about the equilibrium point, the details of postwhirl orbit and occurance of stable limit cycle can be determined only by using a transient nonlinear analysis.

The determination of hydrodynamic force components depends on the film model used. Most of the above analyses were based on the restrictive assumptions of short or long bearings. The Gümbel and Swift-Stieber (Reynolds) boundary conditions treat the cavitation in a superficial manner. In dynamically loaded bearings, the cavitation boundary will vary in size, shape and location, and therefore, the usual zero pressure and pressure gradient boundary conditions will be inadequate to handle the situation. The instantaneous pressure distribution and the location of film boundaries depend not only on the instantaneous position of the journal due to its motion but also on the history of the location of the cavitation boundaries preceeding the instant under consideration. Jakobsson-Floberg (1957) and Olsson (1965) derived boundary conditions (JFO theory) for film rupture and reformation by imposing conservation of mass within the cavitated region and at the boundaries. The theory assumes that the lubricant is transported through the cavitated region in the form of striations extending between the boundaries. Elrod (1981) introduced a cavitation algorithm which conserves mass through the entire bearing and automatically predicts the film rupture and reformation boundaries. Brewe (1983) and Paranjpe and Goenka (1989) applied this algorithm to analyze dynamically loaded bearings and found excellent agreement with experimental data.

In this present work, the stability of the journal bearing is analyzed using the nonlinear journal motion theory. The cavitation algorithm is used to predict the full film and cavitated regions and to determine the fluid force components. The predicted journal trajectories for the periodic loading patterns using the cavitation algorithm are compared with the predictions using Reynolds boundary conditions for both film rupture and reformation. The main objective of this study is not only to analyze the system response for the dynamic loading pattern; but also to highlight the need for considering the film history during such situations. The effect of mass, amplitude of load variation and journal speed are also investigated for a particular frequency of loading.

\section{Nomenclature}

$a_{p} \quad$ amplitude of periodic loading

c radial clearance

e eccentricity

$\mathrm{F}_{\mathrm{r}} \quad$ radial component of fluid film force

$\mathrm{F}_{\theta} \quad$ circumferential component of fluid film force

g switch function

h film thickness

$\overline{\mathrm{h}}$ nondimensional film thickness $[\mathrm{h} / \mathrm{c}]$

L bearing length

L/D length to diameter ratio of the bearing

M mass of the system

$\overline{\mathrm{M}}$ nondimensional mass parameter $\left[\mathrm{Mc} \omega^{2} / \mathrm{W}_{\mathrm{b}}\right]$

p fluid pressure

$\mathrm{p}_{\mathrm{a}} \quad$ ambient pressure

$\mathrm{p}_{\mathrm{C}} \quad$ cavitation pressure

$\mathrm{R}$ residual

$\mathrm{r}$ bearing radius

$\mathrm{t}$ time

$\mathrm{U}$ net surface velocity

$\mathrm{V}_{\mathrm{f}} \quad$ volume occupied by fluid film

$V_{t}$ total volume of fluid element

W applied load at any instant

$\mathrm{W}_{\mathrm{b}} \quad$ base load of periodic loading

$\mathrm{x}$ co-ordinate axis in circumferential direction

$\mathrm{z}$ co-ordinate axis in axial direction

$\beta \quad$ bulk modulus of fluid

$\Delta \mathrm{x} \quad$ grid spacing in $\mathrm{x}$ direction 


\section{Subscript}

i nodes in circumferential direction

j nodes in axial direction

0 initial value

\section{Superscript}

\section{n iteration number}

* current value

\section{Reynolds Equation}

The pressure profile of the fluid film within the bearing clearance is governed by Reynolds equation, which is written in two dimensional, unsteady form, as

$$
\frac{\partial \mathrm{h}}{\partial \mathrm{t}}+\frac{\partial}{\partial \mathrm{x}}\left(\frac{\mathrm{U}}{2} \mathrm{~h}\right)-\frac{\partial}{\partial \mathrm{x}}\left(\frac{\mathrm{h}^{3}}{12 \mu} \frac{\partial \mathrm{p}}{\partial \mathrm{x}}\right)-\frac{\partial}{\partial \mathrm{z}}\left(\frac{\mathrm{h}^{3}}{12 \mu} \frac{\partial \mathrm{p}}{\partial \mathrm{z}}\right)=0
$$

The above differential equation is applicable only within the full film region. The Reynolds boundary conditions to determine the extent of film region can be expressed as

$$
\begin{gathered}
\mathrm{p}\left(\mathrm{x}_{1}, \mathrm{z}\right)=\mathrm{p}\left(\mathrm{x}_{2}, \mathrm{z}\right)=0 \\
\frac{\partial \mathrm{p}}{\partial \mathrm{x}}\left(\mathrm{x}_{1}, \mathrm{z}\right)=\frac{\partial \mathrm{p}}{\partial \mathrm{x}}\left(\mathrm{x}_{2}, \mathrm{z}\right)=0
\end{gathered}
$$

where $\mathrm{x}_{1}$ and $\mathrm{x}_{2}$ are the circumferential coordinates corresponding to film rupture and reformation respectively.

\section{Universal Equation}

Elrod and Adams (1974) developed an "universal equation" which conserves mass and is applicable for both full film and cavitated regions and also across the boundaries. The two dimensional form of the universal equation can be written as

$$
\frac{\partial(\theta \mathrm{h})}{\partial \mathrm{t}}+\frac{\partial}{\partial \mathrm{x}}\left(\frac{\mathrm{hU} \theta}{2}-\frac{\beta \mathrm{h}^{3}}{12 \mu} \mathrm{g} \frac{\partial \theta}{\partial \mathrm{x}}\right)+\frac{\partial}{\partial \mathrm{z}}\left(-\frac{\beta \mathrm{h}^{3}}{12 \mu} \mathrm{g} \frac{\partial \theta}{\partial \mathrm{z}}\right)=0
$$

where the independent variable $\theta$ is defined as

$$
\theta=\left\{\begin{array}{l}
\frac{\rho}{\rho_{\mathrm{c}}} \text { in full film region }(\theta \geq 1) \\
\frac{\mathrm{V}_{\mathrm{f}}}{\mathrm{V}_{\mathrm{t}}} \text { in cavitated region }(\theta<1)
\end{array}\right.
$$

$\mathrm{g}$, the switch function introduced to remove the pressure gradient term in the cavitated region is defined as

$$
g=\left\{\begin{array}{l}
1 \text { in full film region }(\theta \geq 1) \\
0 \text { in cavitated region }(\theta<1)
\end{array}\right.
$$

and the bulk modulus $\beta$ which relates the pressure and density of the liquid is defined as

$$
\beta=\rho \frac{\partial \mathrm{p}}{\partial \rho}=\theta \frac{\partial \mathrm{p}}{\partial \theta}
$$

Since, the mass conservation through the entire bearing is taken into account via the universal equation, the boundary conditions for film rupture and reformation need not be explicitly specified. Within the full film region $(g=1)$, equation (3) results in a compressible form of the Reynolds equation.

Assuming that the bearing is stationary, in the case of statically loaded bearings the surface velocity is only due to the rotation of the journal. In dynamically loaded bearings, the journal center also moves (whirls). In such cases, superimposing the motion of journal on the rotation, the net surface velocity will be

$$
\mathrm{U}=\mathrm{r}\left(\omega-2 \frac{\mathrm{d} \phi}{\mathrm{dt}}\right)
$$

Since the journal motion is superimposed on the rotation, the angular frame of reference remains constant (say maximum film thickness) and the film thickness is determined from

$$
\overline{\mathrm{h}}=1+\varepsilon \cos \psi
$$




\section{Equations of Journal Motion}

For a journal at a position other than its equilibrium position, the plane motion, due to the unbalanced fluid forces, is described by the following scalar nonlinear equilibrium equations, along and normal to the line of centers (fig. 1), respectively,

$$
\begin{gathered}
\mathrm{Mc}\left[\frac{\mathrm{d}^{2} \varepsilon}{\mathrm{dt}^{2}}-\varepsilon\left(\frac{\mathrm{d} \phi}{\mathrm{dt}}\right)^{2}\right]=-\mathrm{F}_{\mathrm{r}}+\mathrm{W} \cos \phi \\
\operatorname{Mc}\left[\varepsilon \frac{\mathrm{d}^{2} \phi}{\mathrm{dt}^{2}}+2\left(\frac{\mathrm{d} \phi}{\mathrm{dt}}\right)\left(\frac{\mathrm{d} \varepsilon}{\mathrm{dt}}\right)\right]=\mathrm{F}_{\theta}-\mathrm{W} \sin \phi
\end{gathered}
$$

The fluid film forces $\mathrm{F}_{\mathrm{r}}$ and $\mathrm{F}_{\boldsymbol{\theta}}$ are determined from integrating the pressure distribution, which is obtained by solving equations (1) or (3) and using the following integrals

$$
\begin{gathered}
\mathrm{F}_{\mathrm{r}}=-\int_{-\mathrm{L} / 2}^{\mathrm{L} / 2} \int_{0}^{2 \pi} \mathrm{p} \cos \psi \mathrm{d} \psi \mathrm{dz} \\
\mathrm{F}_{\theta}=\int_{-\mathrm{L} / 2}^{\mathrm{L} / 2} \int_{0}^{2 \pi} \mathrm{p} \sin \psi \mathrm{d} \psi \mathrm{dz}
\end{gathered}
$$

\section{Periodic Load}

The type of periodic dynamic loading envisaged is of sinusoidal variation, according to the following relationship

$$
\mathrm{W}=\mathrm{W}_{\mathrm{b}}\left[1+\mathrm{a}_{\mathrm{p}} \sin \left(\omega_{\mathrm{p}} \mathrm{t}\right)\right]=\mathrm{W}_{\mathrm{b}}\left[1+\mathrm{a}_{\mathrm{p}} \sin (\Omega \omega t)\right]
$$

where $W_{b}$ is the base load, $a_{p}$ is the amplitude coefficient, $\omega_{p}$ is the frequency of periodic loading and $\Omega$ is the ratio of load cycle frequency to journal frequency.

\section{Numerical Formulation}

\section{Cavitation Algorithm}

A modified cavitation algorithm, an offshoot of the Elrod algorithm, using type differencing procedure was developed by Vijayaraghavan and Keith (1989). The resulting formulation is simply stated below as the details of the development can be obtained from this paper.

Convection Flow. - The convection flow term exists both in the full film and cavitated regions. This term is to be one sided upwind differenced in the cavitated region and is centrally differenced in the full film region.

$$
\begin{aligned}
\left(\frac{\mathrm{U}}{2} \frac{\delta}{\delta \mathrm{x}}(\theta \mathrm{h})\right)_{\mathrm{i}} & =\frac{\mathrm{U}}{2} \frac{1}{2 \Delta \mathrm{x}}\left[\mathrm{g}_{\mathrm{i}+1 / 2}(\theta \mathrm{h})_{\mathrm{i}+1}\right. \\
& +\left(2-\mathrm{g}_{\mathrm{i}+1 / 2}-\mathrm{g}_{\mathrm{i}-1 / 2}\right)(\theta \mathrm{h})_{i}-\left(2-\mathrm{g}_{\mathrm{i}-1 / 2}\right)(\theta \mathrm{h})_{\mathrm{i}-1}
\end{aligned}
$$

where

$$
g_{i \pm 1 / 2}=\frac{g_{i}+g_{i \pm 1}}{2}
$$

The above formulation is based on the implicit assumption that the surface velocity $U$ is positive. However, if the velocity is negative, then this flow term must remain one sided upwind differenced in the cavitated region (thus, forward differenced relative to original grid scheme), to properly describe the physics of the problem. In such cases, the following formulation shall be used

$$
\begin{aligned}
\left(\frac{\mathrm{U}}{2} \frac{\delta}{\delta \mathrm{x}}(\theta \mathrm{h})\right)_{\mathrm{i}} & =\frac{\mathrm{U}}{2} \frac{1}{2 \Delta \mathrm{x}}\left[\left(2-\mathrm{g}_{\mathrm{i}+1 / 2}\right)(\theta \mathrm{h})_{\mathrm{i}+1}\right. \\
& \left.-\left(2-\mathrm{g}_{\mathrm{i}+1 / 2}-\mathrm{g}_{\mathrm{i}-1 / 2}\right)(\theta \mathrm{h})_{\mathrm{i}}-\mathrm{g}_{\mathrm{i}-1 / 2}(\theta \mathrm{h})_{\mathrm{i}-1}\right]
\end{aligned}
$$

When the surface velocity reverses during the course of the computation, equations (11) and (12) can be combined and written in a more compact and efficient form as

$$
\begin{aligned}
& \left(\frac{\mathrm{U}}{2} \frac{\delta}{\delta \mathrm{x}}(\theta \mathrm{h})\right)_{\mathrm{i}}=\frac{\mathrm{U}}{2} \frac{1}{2 \Delta \mathrm{x}}\left[(\theta \mathrm{h})_{\mathrm{i}+1}-(\theta \mathrm{h})_{\mathrm{i}-1}\right]+\frac{|\mathrm{U}|}{2} \frac{1}{2 \Delta \mathrm{x}} \\
& \times\left[\left(\mathrm{g}_{\mathrm{i}+1 / 2}-1\right)(\theta \mathrm{h})_{\mathrm{i}+1}+\left(2-\mathrm{g}_{\mathrm{i}+1 / 2}-\mathrm{g}_{\mathrm{i}-1 / 2}\right)(\theta \mathrm{h})_{\mathrm{i}}+\left(\mathrm{g}_{\mathrm{i}+1 / 2}-1\right)(\theta \mathrm{h})_{\mathrm{i}-1}\right]
\end{aligned}
$$

Since the formulation of equation (3) is based on the assumption of a compressible film, the resulting algorithm also has $\theta$ in the full film region. For sufficiently large values of $\beta$, the $\theta$ values will be very close to unity and hence this assumption does not introduce appreciable error. Alternately, while writing the code, the effect of $\theta$ can be neglected in the full film region $\left(\mathrm{g}_{\mathrm{i}-1}=\mathrm{g}_{\mathrm{i}}=\mathrm{g}_{\mathrm{i}+1}=1\right)$ resulting in a formulation equivalent to $\partial \mathrm{h} / \partial \mathrm{x}$. Also, in order to ensure one sided differencing near the reformation boundary, i.e., when $g_{i-1}=g_{i}=0, g_{i+1}=1, U>0 ; g_{i+1 / 2}$ is set to zero.

Pressure Induced Flow.-The pressure induced flow term in the $\mathrm{x}$ direction is differenced as

$$
\begin{aligned}
\frac{\delta}{\delta \mathrm{x}}\left(-\mathrm{h}^{3} \mathrm{~g} \frac{\delta \theta}{\delta \mathrm{x}}\right)_{i} & =-\frac{1}{\Delta \mathrm{x}^{2}}\left[\mathrm{~h}_{\mathrm{i}+1 / 2}^{3} \mathrm{~g}_{\mathrm{i}+1}\left(\theta_{\mathrm{i}+1}-1\right)\right. \\
& \left.-\left(\mathrm{h}_{\mathrm{i}+1 / 2}^{3}+\mathrm{h}_{\mathrm{i}+1 / 2}^{3}\right) \mathrm{g}_{\mathrm{i}}\left(\theta_{\mathrm{i}}-1\right)+\mathrm{h}_{\mathrm{i}-1 / 2}^{3} \mathrm{~g}_{\mathrm{i}-1}\left(\theta_{\mathrm{i}-1}-1\right)\right]
\end{aligned}
$$


The expression for the flow in the $\mathrm{z}$ direction can be written in similar fashion.

\section{Numerical Procedure}

\section{Reynolds Equation}

Equation (1) is discretized in finite difference forms in terms of the unknown variable $p$ and numerically solved using a successive relaxation procedure either in explicit or implicit form. When the finite difference formulation is cast in successive line over relaxation (SLOR) form, the resulting algebraic equations can be written as

$$
A_{i, j} p_{i-1, j}^{n+1}+B_{i, j} p_{i, j}^{n+1}+C_{i, j} p_{i+1, j}^{n+1}=D_{i, j} p_{i, j-1}^{n}+E_{i, j} p_{i, j+1}^{n}+F_{i, j}
$$

where the coefficients $A_{i, j}, B_{i, j}$ and $C_{i, j}$, and right hand side of equation (15) are known. The subscripts $i$ and $j$ represent grid points in the circumferential and axial directions respectively and $\mathrm{n}$ denotes the iteration number. The system of equations for every $j$ are simultaneously solved. After one sweep is completed, the resulting negative pressures are set to zero. The procedure is repeated until the pressure values have converged according to the following convergence criteria

$$
\frac{\left|\Sigma p_{i, j}^{n+1}-\Sigma p_{i, j}^{n}\right|}{\Sigma p_{i, j}^{n}} \leq 10^{-3}
$$

\section{Cavitation Algorithm}

In order to obtain time-accurate transient solutions, equation (3) is solved using equations (13) and (14) by combining an approximate factorization method with a Newton iteration procedure. The details of the procedure are discussed in detail by Vijayaraghavan and Keith (1990). Hence, only the overall idea is presented here.

Equation (3) is a function of $\theta$ only and can be represented by

$$
\mathbf{f}(\theta)=0
$$

where $\mathbf{f}$ is an operator for equation (3). The Newton iteration for a solution to equation (17) is,

$$
\mathbf{f}\left(\theta^{*}\right)+\left(\frac{\partial \mathbf{f}}{\partial \theta}\right)_{\theta=\theta^{*}}\left(\theta-\theta^{*}\right)=0
$$

where $\theta *$ is the currently available value of $\theta$. At every time level, iteration is carried out by updating $\theta *$ until $\Delta \theta=$ $(\theta-\theta *)$ approaches zero.

Equation (3) applied to equation (18) produces

$$
\left[\frac{\mathrm{h}}{\Delta \mathrm{t}}+\frac{\partial}{\partial \mathrm{x}} \mathrm{a}_{10}+\frac{\partial}{\partial \mathrm{x}}\left(\mathrm{a}_{11}\right) \frac{\partial}{\partial \mathrm{x}}+\frac{\partial}{\partial \mathrm{z}}\left(\mathrm{a}_{22}\right) \frac{\partial}{\partial \mathrm{z}}\right] \Delta \theta+\mathbf{f}(\theta)_{\theta=\theta^{*}}=0
$$

where $\mathrm{a}_{10}=\frac{\mathrm{U}}{2} \mathrm{~h}, \mathrm{a}_{11}=\mathrm{a}_{22}=-\frac{\beta}{12 \mu} \mathrm{h}^{3} \mathrm{~g}$

Equation (19) can written in the following operator form

$$
\mathbf{N} \Delta \theta+\mathrm{R}=0
$$

where $\mathbf{N}$ is an operator, $\Delta \theta=\left(\theta^{\mathrm{n}+1}-\theta^{*}\right)$ is the correction and $\mathrm{R}$ is the residual at $\theta *$, or, a measure of how well equation (3) is satisfied at $\theta *$. The operator $\mathbf{N}$ is defined as a product of two operators, which are approximate factors of $\mathbf{f}$ and written as

where

$$
\mathbf{N}=\mathrm{BN}_{\mathbf{x}} \mathbf{N}_{\mathbf{z}}
$$

$$
\begin{aligned}
& \mathbf{N}_{\mathbf{X}}=1+\frac{1}{\mathrm{~B}} \frac{\partial}{\partial \mathrm{x}} \mathrm{a}_{10}+\frac{1}{\mathrm{~B}} \frac{\partial}{\partial \mathrm{x}}\left(\mathrm{a}_{11}\right) \frac{\partial}{\partial \mathrm{x}} \\
& \mathbf{N}_{\mathrm{Z}}=1+\frac{1}{\mathrm{~B}} \frac{\partial}{\partial \mathrm{z}}\left(\mathrm{a}_{22}\right) \frac{\partial}{\partial \mathrm{z}} \\
& \mathrm{B}=\frac{\mathrm{h}}{\Delta \mathrm{t}}
\end{aligned}
$$

The solution is obtained in two steps as follows

$$
\begin{array}{ll}
\text { Step 1: } & \mathbf{N}_{\mathbf{X}} \Delta \bar{\theta}=-\frac{\mathrm{R}}{\mathrm{B}} \\
\text { Step 2: } & \mathbf{N}_{\mathbf{Z}} \Delta \theta=\Delta \bar{\theta}
\end{array}
$$

In the first step, $\overline{\Delta \theta}$ is obtained by sweeping in the $\mathrm{x}$ direction (along a constant axial co-ordinate line). The final value of correction $\Delta \theta$ is obtained in the second step by sweeping in the $\mathrm{z}$ direction (along a constant circumferential co-ordinate line). The approximate factorization technique has been found to be robust and efficient .

\section{Equations of Motion}

Equations (6) and (7) are two scalar, coupled, nonlinear ordinary differential equations. These equations are integrated 
simultaneously using a fourth order Runge-Kutta method for known values of $\mathrm{M}, \mathrm{c}, \mathrm{W}, \mathrm{F}_{\mathrm{r}}$ and $\mathrm{F}_{\theta}$ and initial values of, $\varepsilon$, d $\varepsilon / \mathrm{dt}$ and $\mathrm{d} \phi / \mathrm{dt}$. The fourth order Runge-Kutta method is considered to be the stansard method for solving nonlinear differential equations, paticularly with non-smooth profiles.

The integrations to determine the force components, $\mathrm{F}_{\mathrm{r}}$ and $F_{\theta}$ (eqs. (8) and (9)) are performed using Simpson's Rule.

\section{Solution Procedure}

A submerged journal bearing without any feed groove arrangement is considered in this analysis. The axial ends of the bearing are maintained at ambient pressure and the cavitation pressure is taken to be absolute zero. Due to axial symmetry, only one half of the bearing is analyzed. Initially the bearing is assumed to be filled with lubricant at ambient pressure and released at an arbitrary location other than its equilibrium position (table I). With Reynolds equation, at every time step, a converged pressure distribution is determined. Hence, the pressure distribution is only a function of the instantaneous eccentricity ratio. However, the pressure distribution of the previous time step is considered as the first iteration value, for the purpose of verifying the convergence according to equation (16). Whereas, with the cavitation algorithm no such convergence is sought. The pressure distribution is obtained by marching in time. Equation (3) is solved to determine the current $\theta$ distribution based on the $\theta$ distribution at the previous time step and the current value of the eccentricity ratio. At every time step, the switch function distribution is updated. Thus, oil film history in the cavitated region is taken into account at every time step. The Newton iterations are performed, if necessary, to reduce the residuals to a low level $\left(\mathrm{O}\left(10^{-5}\right)\right)$.

From the pressure profile the force components $F_{r}$ and $F_{\theta}$ are computed. The applied load values at every time step are also determined according to equation (10). Then the equations of motion, i.e., equations (6) and (7), are solved for known values of $\mathrm{M}, \mathrm{c}, \mathrm{W}, \mathrm{F}_{\mathrm{r}}$ and $\mathrm{F}_{\theta}$ and initial values of $\varepsilon, \phi, \mathrm{d} \varepsilon / \mathrm{dt}$ and $\mathrm{d} \phi / \mathrm{dt}$, to determine the new values of $\varepsilon$ and $\phi$. To begin the process, $d \varepsilon / d t$ and $d \phi / d t$ are assumed to be zero. The procedure is repeated and the trajectory of the journal, forces developed by the fluid film, net surface velocity, minimum film thickness and the pressure distribution are recorded at every specified time interval. Analysis with both methods are performed for the same axial boundary conditions, same grid arrangement and same time steps. The computational grid has 49 nodes in circumferential and 15 nodes in axial directions. The codes are vectorized and the CRAY XMP super computer is used. The time step of $10^{-5} \mathrm{sec}$ is used and a typical cpu time on the CRAY was $120 \mathrm{sec}$ per journal revolution. Each case is run for 10 journal revolutions. The time required for one load cycle depends on the frequency ratio, $\Omega$.

\section{Results and Discussion}

To determine the effect of frequency of periodic loading, for the same load cycle, the frequency ratio $\Omega$ is varied from 0.25 to 3.0. The analyses are performed twice, using the cavitation algorithm and Reynolds equation. The solutions from the cavitation algorithm are compared with the solutions of the Reynolds equation with Reynolds boundary conditions.

When $\Omega=0.25$, one load cycle occurs at every four journal revolutions. Figure 2 compares the journal trajectory, fluid film forces, net surface velocity and the minimum film thickness predicted by both methods for this case. Although the journal trajectory predicted by both methods is similar, the cavitation algorithm predicts larger eccentricity values. This can also be observed in the differences in the minimum film thickness values and the transient forces developed by the fluid film. At times, the radial component of the force varies by as much as 30 percent. The cavitation algorithm predicts larger forces and smaller minimum film thickness values. The differences in the variations of net surface velocity between the methods are not significant. However, it is interesting to note that the velocity becomes negative for a brief period of time. During such occasions, it is as though the journal rotates in the opposite direction.

Figure 3 represents the comparison of the journal trajectory, fluid film forces, velocity and minimum film thickness when $\Omega=0.50$. While both methods predict that the journal will attain a limit cycle at high eccentricity values, the cavitation algorithm predicts sharper changes in the trajectory. For this frequency of loading, very large fluid film forces are predicted by the cavitation algorithm. The radial component of the force attains values as much as three times the values predicted when $\Omega=0.25$ (fig. 2). Reynolds boundary conditions do not predict such high excursions in forces, although the peaks are about doubled compared to the case for $\Omega=0.25$. Large excursions in minimum film thickness are predicted by the cavitation algorithm, although the minimum-minimum values are smaller. The net surface velocity variations are similar, except during the initial journal orbit, at which time the net surface velocities are of opposite sign. If the motion of the journal center encloses the bearing center, the angular velocity of the journal and the angular velocity of the journal center have the same sign. Thus, according to equation (4), when the angular velocity of the journal center exceeds the angular velocity of the journal, the net velocity becomes negative. In this case, the cavitation algorithm predicts an initial journal center orbit that did not enclose the bearing center. Thus the downward motion of the journal center was of opposite sign to the rotational direction resulting in a positive net surface velocity. In this case also, the net surface velocity alternates between positive and negative values. With the cavitation algorithm, this situation causes a cavitated region to be formed at both sides of the pressure hump. Instantaneous pressure 
profiles at four events are presented in figures $4(\mathrm{a})$ and (b). Figure 4(a) is the pressure profiles predicted by the cavitation algorithm during the third load cycle when (1) the the pressure developed is minimum, (2) the pressure developed is maximum, (3) eccentricity is maximum and (4) the applied load is zero. Figure 4(b) also indicates the same events predicted using Reynolds boundary conditions, but at different times. The instantaneous journal position and its cumulative trajectory are also indicated in the figures. Generally, the cavitation algorithm predicts larger pressure values and larger cavitated regions. Reynolds boundary conditions do not predict any cavitated region at minimum pressure, nor does it predict two cavitated regions split by a high pressure fluid film region for conditions (2) and (3) (figs. 4(a) and (b)). During this loading pattern, the pressure profile and the cavitated regions undergo dramatic variations in shape, size and locations.

As shown in figure 5 , when $\Omega=1.0$, the journal trajectory predicted by both methods are quite different. The cavitation algorithm predicts a limit cycle around the bearing center line while the predictions using Reynolds boundary conditions indicate the movement of the journal limited to one side of the bearing, the amplitude of the motion becoming progressively smaller as it converges to a smaller eccentricity ratio. With this frequency of loading, the force levels are much smaller and the excursions are considerably reduced as compared to the condition with $\Omega=0.5$. The minimum film thickness predicted by the cavitation algorithm is also much smaller.

Figure 6 is the representation of the conditions when $\Omega=$ 2.0. When the cavitation algorithm is used, the journal barely passes through the bearing center and the excursions are slightly reduced with time. The predictions using Reynolds boundary conditions indicate the journal movement was limited to one side of the clearance circle and the journal excursions reduce with time. The minimum film thickness predicted by the cavitation algorithm also has wide fluctuations, with smaller minimum values.

The transient conditions for $\Omega=3.0$ are shown in figure 7. The journal trajectory predicted using the cavitation algorithm has much smaller excursions as compared to the trajectory predicted using Reynolds boundary conditions. In both cases, the journal movement is limited to one side of the clearance circle, with the amplitude of motion diminishing with time. With Reynolds boundary conditions, the journal trajectories for both $\Omega=2.0$ and $\Omega=3.0$ are similar. Further increases in the loading frequency produces nearly similar journal trajectories using both methods. Due to the high frequency of periodic loading, the variations in load values occur before the fluid film can react to such variations. Hence, the journal trajectories almost simulate the condition of a constant load.

In all the above cases, the cavitation algorithm predicts smaller minimum-minimum film thickness values and large fluid film forces. When the dynamic loading pattern undergoes such large variations, the memory effect of fluid film becomes an important criteria. Modeling the problem accounting for mass conservation and consideration of cavitation regions are very important during such situations. With periodic loading, the journal generally attains a limit cycle, the limit cycle being smaller when the frequency of the periodic loading is larger.

Having analyzed the effect of periodic loading on the perfonnance of the journal bearing, it is desired to investigate the effects of other parameters, viz., mass of the system, amplitude of load variation and journal speed, on the stability of the bearing. The case of $\Omega=0.5$ is considered for this study due to the occurance of large excursions in the forces during this loading frequency. Only the cavitation algorithm is utilized for this study.

The mass of the system is varied from one tenth to five times the value used for the frequency effect study. The journal trajectories are shown in figure 8 . When $\bar{M}=0.5$, the journal trajectory almost immediately settles into a limit cycle; but only on one side of the clearance circle. When $\bar{M}=2.5$, the journal oscillations grow with time and approach a limit cycle around the bearing center. When the mass parameter is larger, the journal trajectory attains the limit cycle faster and at very high eccentricity ratios. Figure 9 compares the transient variations in minimum film thickness for various mass parameter values. With larger mass, the fluctuations are diminished but the minimum-minimum film thickness values are very small, nearly touching the bearing surface.

The periodic load amplitude was varied from unity to zero. The journal trajectories are indicated in figure 10. With smaller amplitude, the journal movements are only on one side of the clearance circle. The smaller the amplitude the smaller the journal excursion and the region of limit cycle. This zero amplitude case essentially represents a unidirectional constant load. The journal oscillations are damped out and it will eventually reach its equilibrium position. The variations in minimum film thickness are indicated in figure 11. For smaller amplitudes, the minimum film thickness variations are smaller and the mean values are higher as compared to those at larger amplitudes.

The effect of variations in journal speed is presented in figure 12 . The frequency ratio $\Omega$ is, however, maintained at 0.5 . With the lower journal speed, the trajectory is on one side of the bearing; however, growing in the amplitude of oscillation. When the journal speed is increased, the journal moves around the bearing center, attaining a limit cycle. However, from the data it was observed that the lowest minimum film thickness is obtained when the journal speed is at $600 \mathrm{rpm}$.

\section{Conclusions}

A nonlinear stability analysis is performed on a system supported by a plain journal bearing, under periodic dynamic loading. A cavitation algorithm was used which conserves mass and takes the oil film history into account. These 
solutions were compared with the solutions of Reynolds equation using Reynolds boundary conditions for various loading frequencies, amplitude of periodic loading, mass parameter and journal speed. Comparisons on the journal trajectories, fluid film forces, net surface velocity, minimum film thickness and pressure profiles are presented.

(1) It was established that the oil film history is important for these complex loading patterns.

(2) With periodic loading, the journal almost always attains a stable limit cycle. When the periodic loading frequency is half of the journal frequency, very large fluid forces are developed and the journal whirls at large eccentricity ratios. With further increase in frequency of loading, the film forces are diminished, the journal oscillations are reduced and its movement is restricted to only one side of the clearance circle.

(3) The mass plays a major part in the system response to the loading pattern. With smaller mass, the generation of large fluid film forces are avoided and the journal attains a stable, smaller limit cycle.

(4) The amplitude of load variation also has a pronounced effect on the stability of the system. The smaller the periodic load amplitude, the smaller the journal excursions and film force levels.

Stability analysis of dynamic loading patterns is very important for designers in order for them to understand system response. Nonlinear transient analysis and consideration of cavitation effects along with oil film history are imperative for such studies to model the system as close to the practical situation as possible.

\section{References}

Akers, A.; Michaelson, S.; and Cameron, A.: Stability Contours for a Whirling Finite Joumal Bearing. J. Lubr. Technol., vol. 93, no. 1, 1971, pp. 177-190.
Allaire, P. E.: Design of Joumal Bearings for High Speed Rotating Machinary. Fundamentals of the Design of Fluid Film Bearings, S.M. Rohde, et al., eds., ASME, pp. 45-83.

Badgley, R. H.; and Booker, J. F.: Turborotor Instability: Effects of Initial Transients on Plane Motion. J. Lubr. Technol., vol. 91, no. 4, 1965, pp. 625-633.

Booker, J. F.: Dynamically Loaded Joumal Bearings - Mobility Method of Solution. J. Basic Eng., vol. 87, no. 3, 1965, pp. 537-546.

Brewe, D. E.: Theoretical Modeling of the Vapor Cavitation in Dynamically Loaded Joumal Bearings. J. Tribol., vol. 108, no. 4, 1986, pp. 628-638.

Capriz, G.: 1965 see communications on Mitchell et al., 1965.

Elrod, H.G., Jr.; and Adams, M.L.: A Computer Program for Cavitation and Starvation Problems. Cavitation and Related Phenomena in Lubrication, Mechanical Engineering Publications, New York, 1974, pp. 37-41.

Elrod, H.G., Jr.: A Cavitation Algorithm. J. Lubr. Technol., vol. 103, no. 3 , 1981, pp. 350-354.

Holmes, R.: The Vibration of a Rigid Shaft on Short Sleeve Bearings. J. Mech. Eng. Sci., vol. 2, no. 4, 1960, pp. 337-341.

Jakobsen, K.; and Christensen, H.: Non-Linear Transient Vibrations in Joumal Bearings. Tribology Convention 1969, Proc. Inst. Mech. Eng., vol. 183, pt. 3P, 1968-69, pp. 50-56.

Jakobsson, B.; and Floberg, L.: The Finite Joumal Bearing, Considering Vaporization. Transactions of Chalmers University of Technology, No. 190, Guthenberg, Sweden, 1957.

Kirk, R; and Gunter, E. J.: Transient Joumal Bearing Analysis. NASA CR-1549, 1970.

Majumdar, B. C.; and Brewe, D. E.: Stability of a Rigid Rotor Supported on Oil Film Joumal Bearings Under Dynamic Load. NASA TM-102309 (AVSCOM TR 87-C-26). 1987.

Mitchell, J. R.; Holmes, R; and Byrne, J.: Oil Whirl of a Rigid Rotor in $360^{\circ}$ Joumal Bearings : Further Characteristics. Proc. Inst. Mech. Eng., vol. 180, pt. 1, no. 25, 1965-66, pp. 593-610.

Olsson, K.O.: Cavitation in Dynamically Loaded Bearing, Transactions of Chalmers University of Technology, No. 308, Guthenberg, Sweden, 1965.

Paranjpe, R.S.; and Goenka, P.K.: Analysis of Crankshaft Bearings Using Mass Conservation Algorithm. Tribology Transactions, vol. 33, Number 3, 1990, pp. 333-344.

Vijayaraghavan,D.; and Keith, Jr., T.G.: Development and Evaluation of a Cavitation Algorithm. Tribol.Trans., vol. 32, no. 2, 1989, pp. 225-233.

Vijayaraghavan, D.; and Keith, Jr. T.G.: An Efficient, Robust, and Time Accurate Numerical Procedure Applied to a Cavitation Algorithm. J. Tribol., vol. 112, no. 1, 1990, pp. 44-51. 
TABLE I.-BEARING DATA

\begin{tabular}{|l|c|l|}
\hline $\mathrm{L} / \mathrm{D}$ & ---- & 0.562 \\
$\mathrm{r}$ & $\mathrm{m}$ & .1 \\
$\mathrm{c}$ & $\mathrm{m}$ & $8.0 \times 10^{-5}$ \\
$\mathrm{p}_{\mathrm{a}}$ & $\mathrm{N} / \mathrm{m}^{2}$ & $1.0133 \times 10^{5}$ \\
$\mathrm{p}_{\mathrm{c}}$ & $\mathrm{N} / \mathrm{m}^{2}$ & .0 \\
$\overline{\mathrm{M}}$ & ---- & 5.0 \\
$\mathrm{a}_{\mathrm{p}}$ & ----- & 1.0 \\
$\mathrm{~W}_{\mathrm{b}}$ & $\mathrm{N}$ & $40 \times 10^{3}$ \\
$\beta$ & $\mathrm{N} / \mathrm{m}^{2}$ & $1.72 \times 10^{8}$ \\
$\mu$ & $\mathrm{Pa} . \mathrm{s}$ & .015 \\
$\omega$ & $\mathrm{rad} / \mathrm{s}$ & $62.84(600 \mathrm{rpm})$ \\
$\Omega$ & ----- & .25 to 3.0 \\
$\varepsilon_{0}$ & ----- & .65 \\
$\phi_{0}$ & ----- & .0 \\
\hline
\end{tabular}

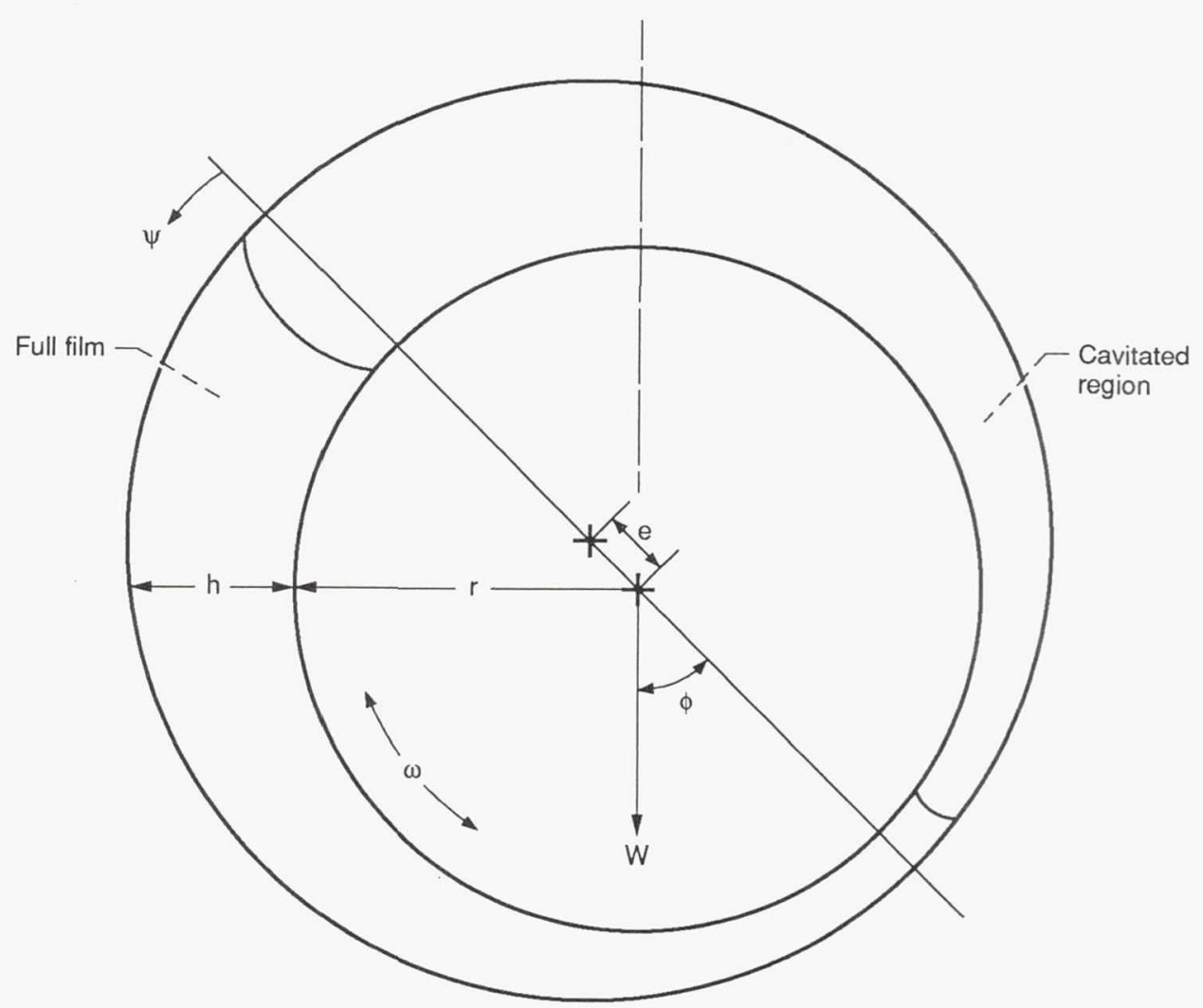

Figure 1. Schematic diagram of journal bearing 


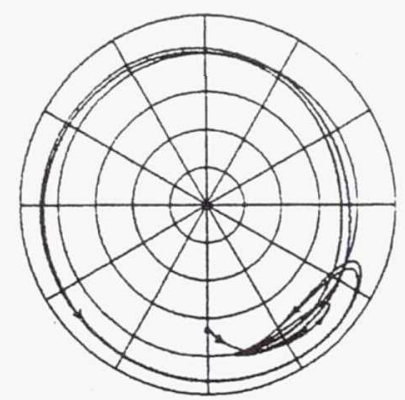

CAUITATION ALGORITHM

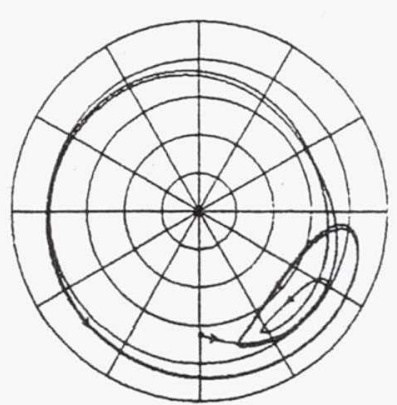

REYNOLOS B.C.

(a) Journal trajectory.

Figure 2.-Periodic loading $(\Omega=0.25)$. 


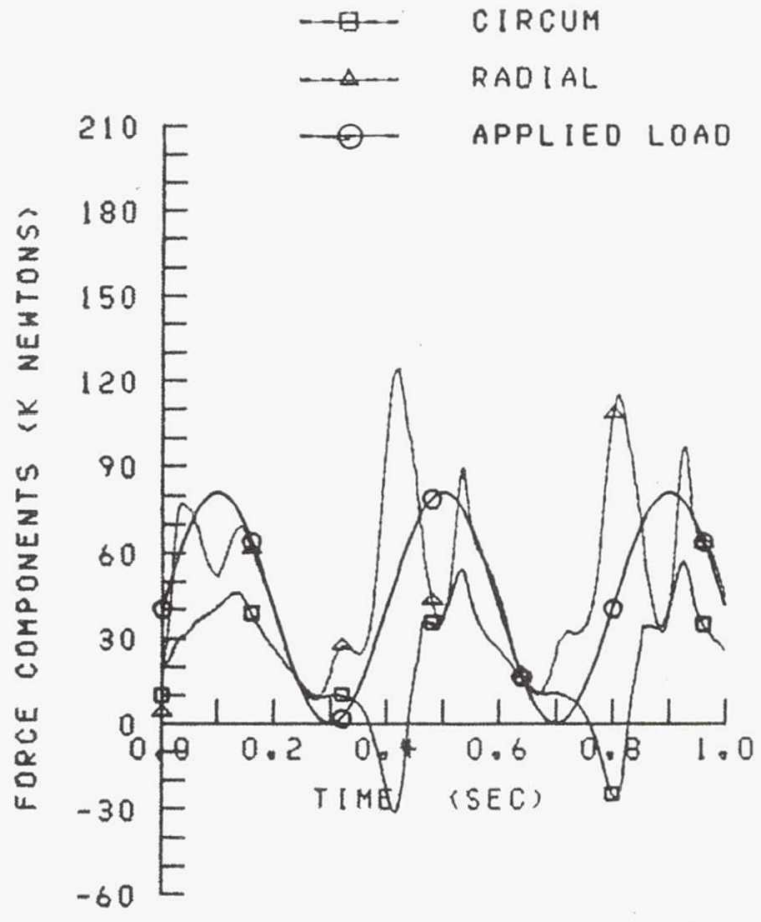

Cavitation algorithm

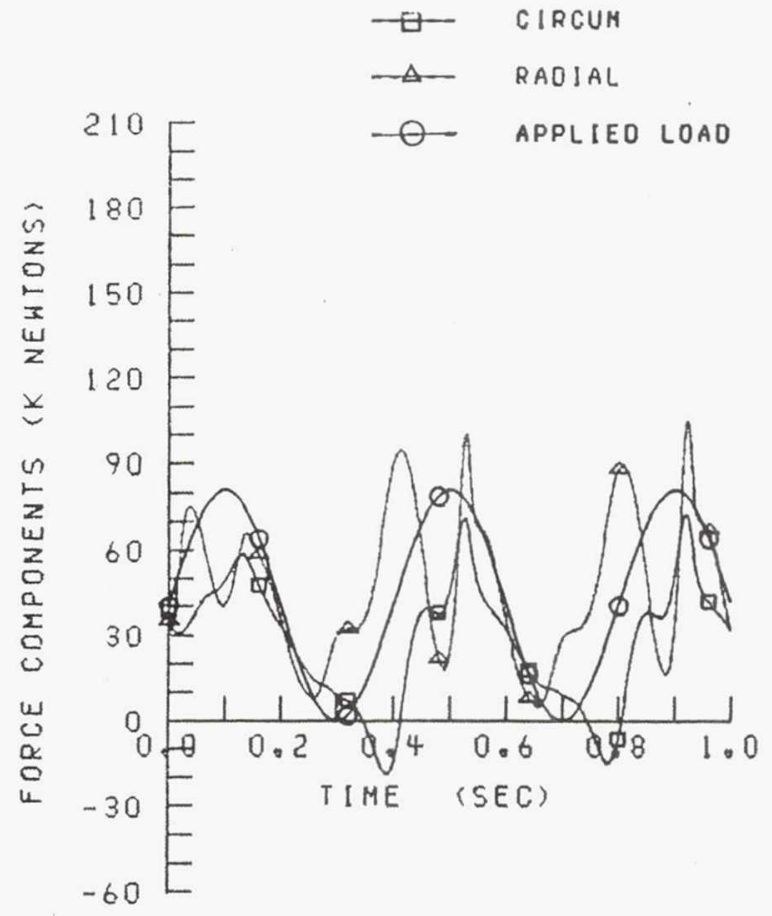

Reynolds B.C.

(b) Fluid film forces.

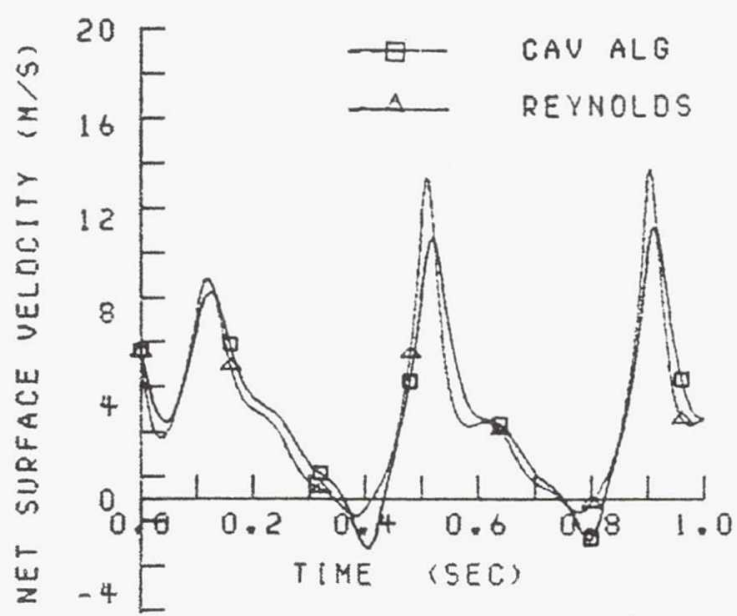

(c) Net surface velocity.

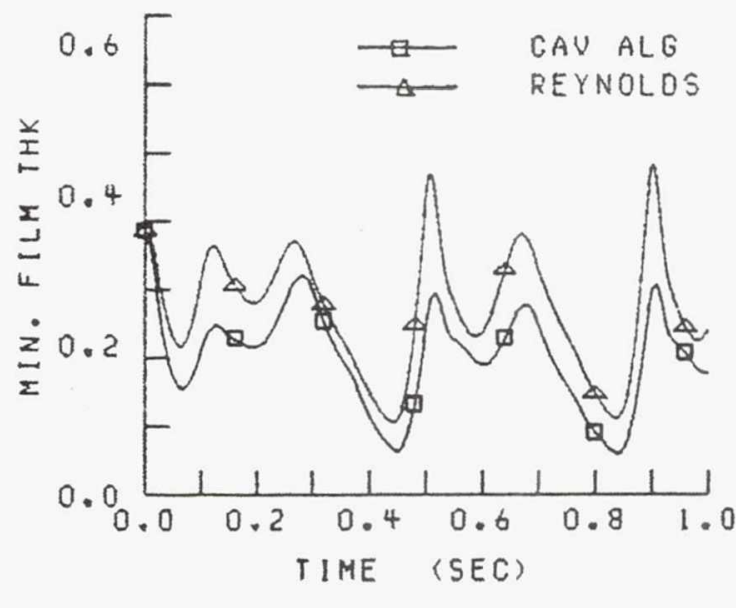

(d) Minimum film thickness.

Figure 2.-Concluded. 

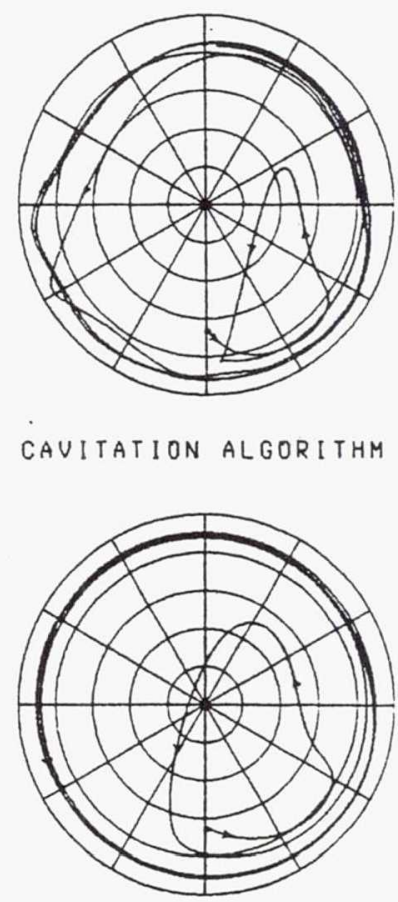

REYNOLOS B.C.

(a) Journal trajectory.

Figure 3.-Periodic loading $(\Omega=0.50)$. 

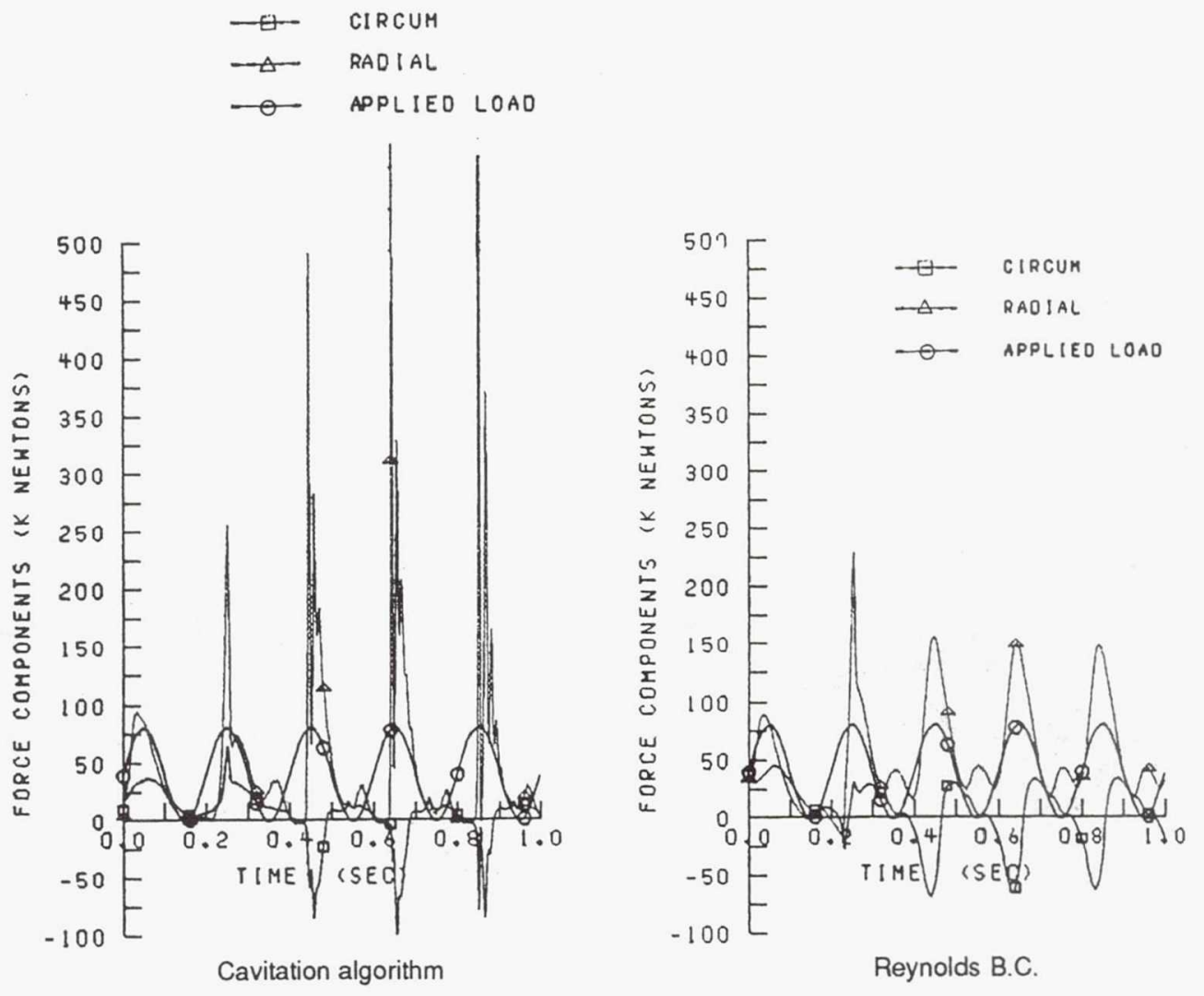

(b) Fluid film forces.

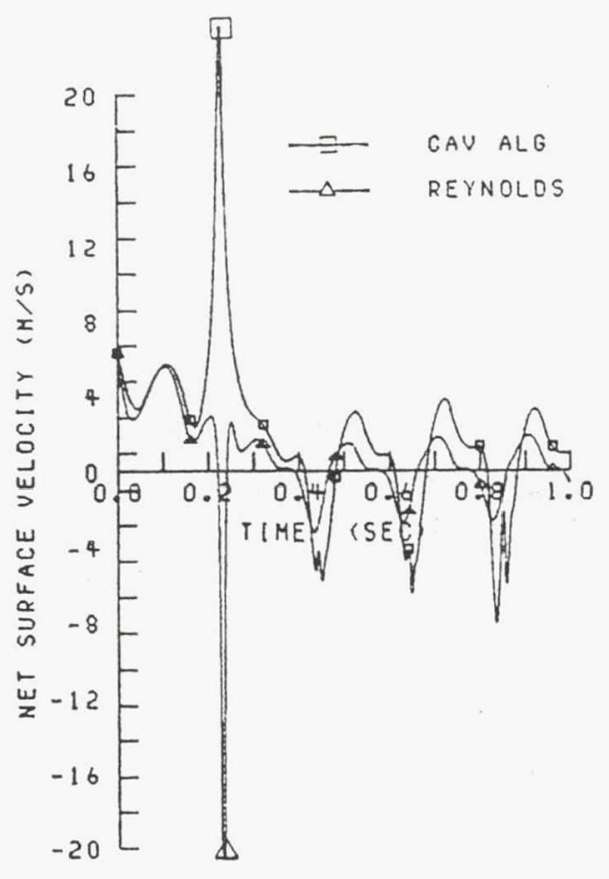

(c) Net surface velocity.

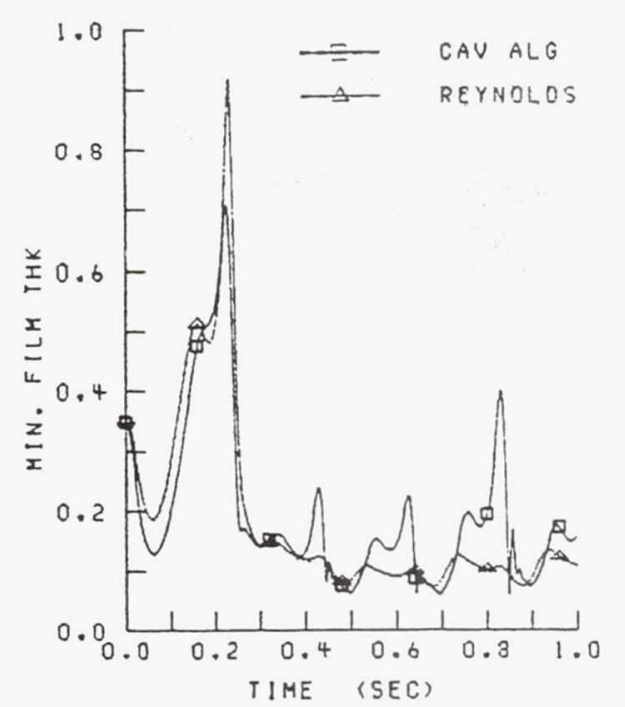

(d) Minimum film thickness.

Figure 3.-Concluded. 


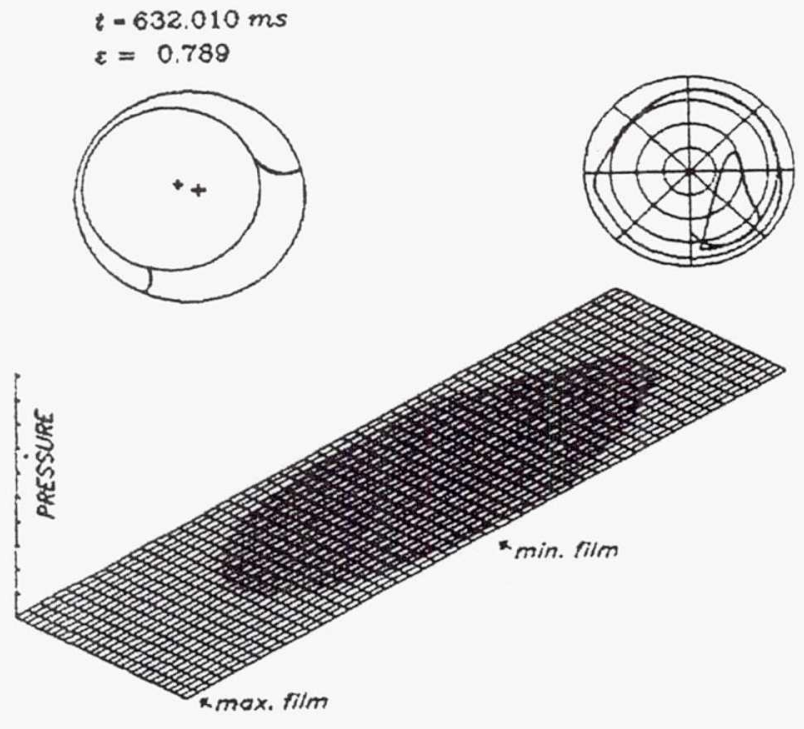

(i) Minimum pressure.

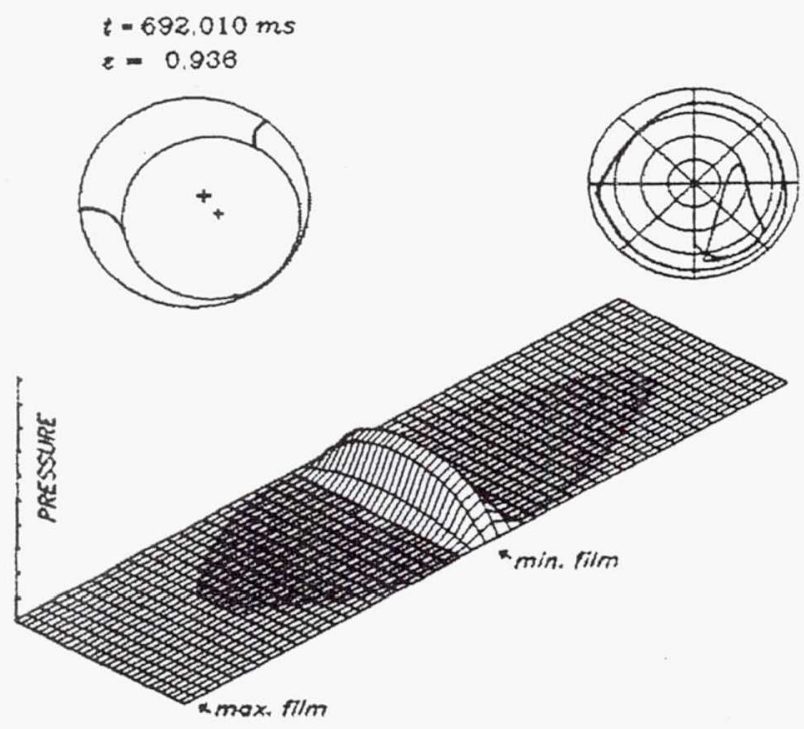

(iii) Maximum eccentricity.

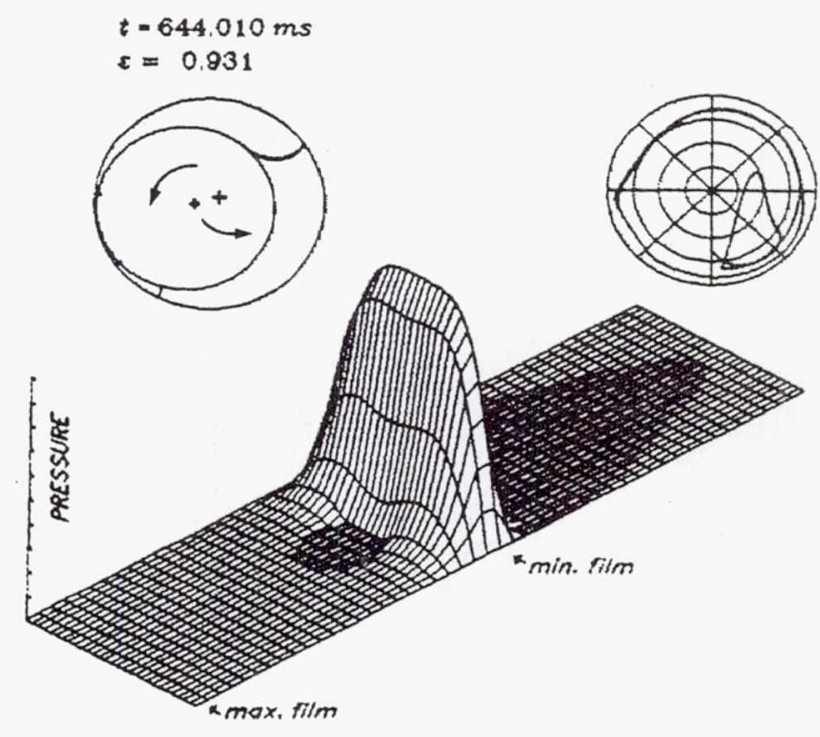

(ii) Maximum pressure.

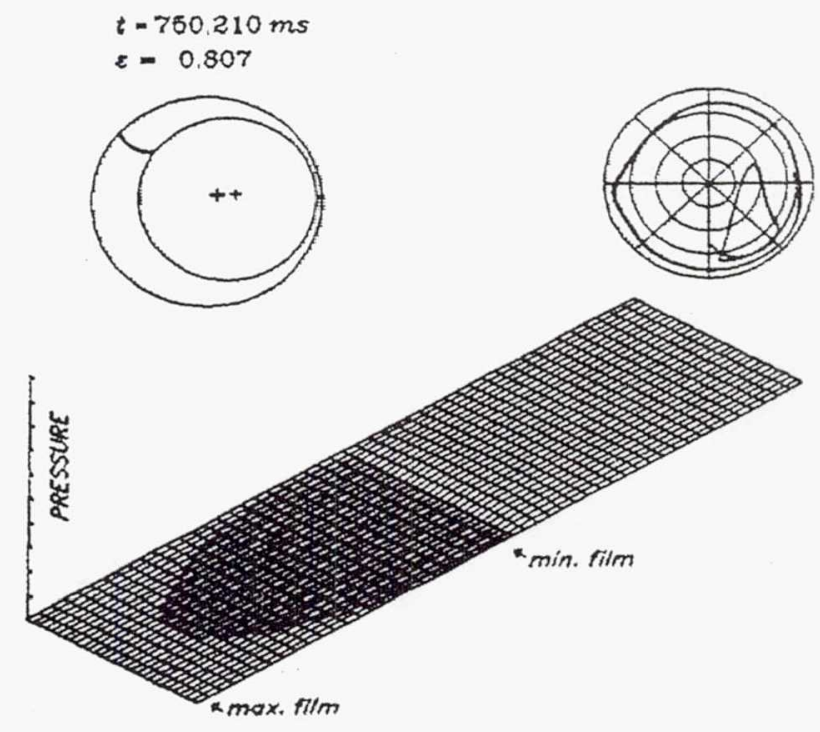

(iv) Zero applied load.

Figure 4a.-Pressure profiles - cavitation algorithm $(\Omega=0.50)$. 


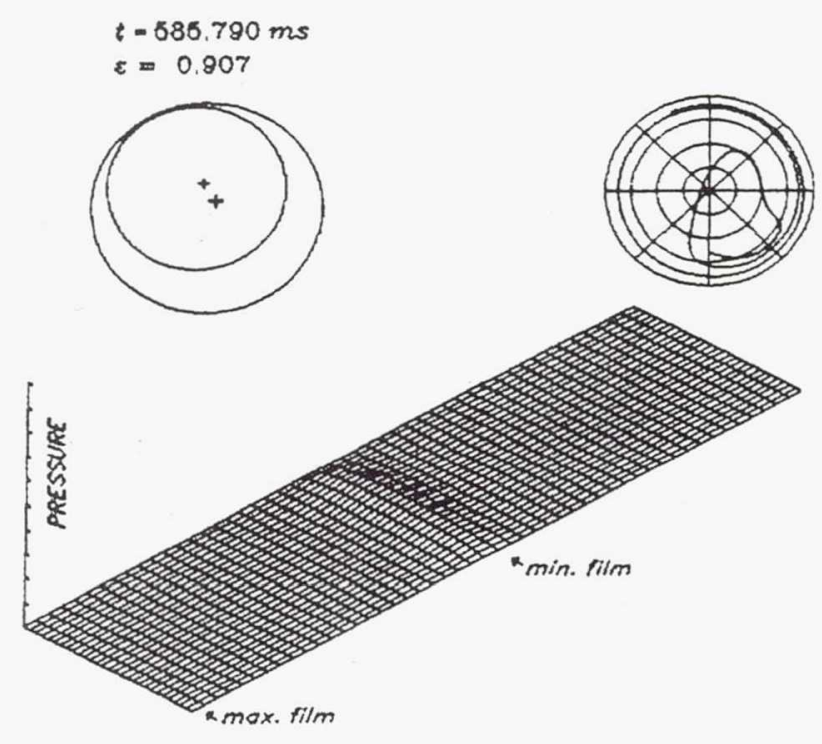

(i) Minimum pressure.

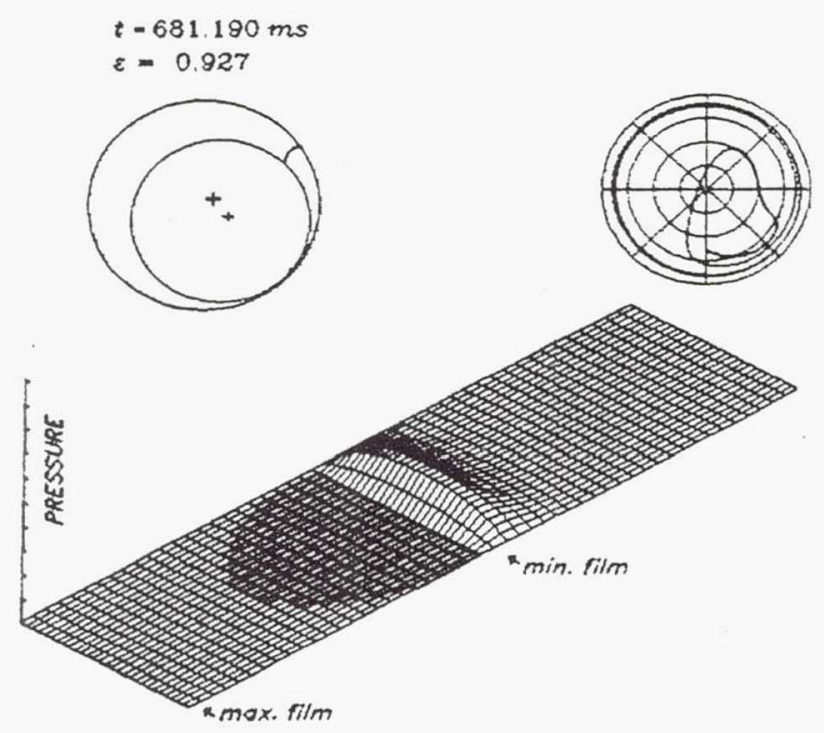

(iii) Maximum eccentricity.

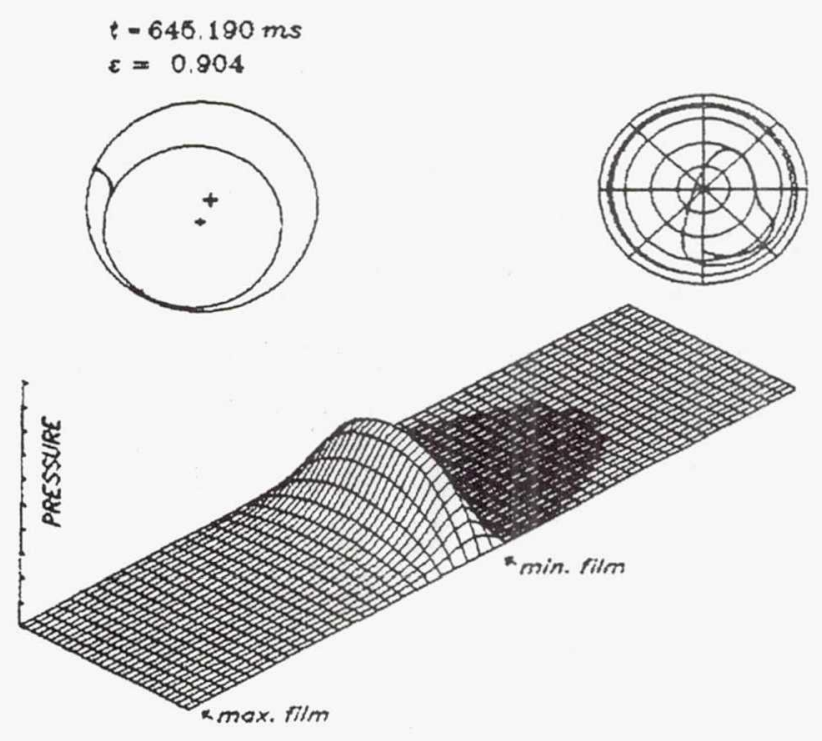

(ii) Maximum pressure.

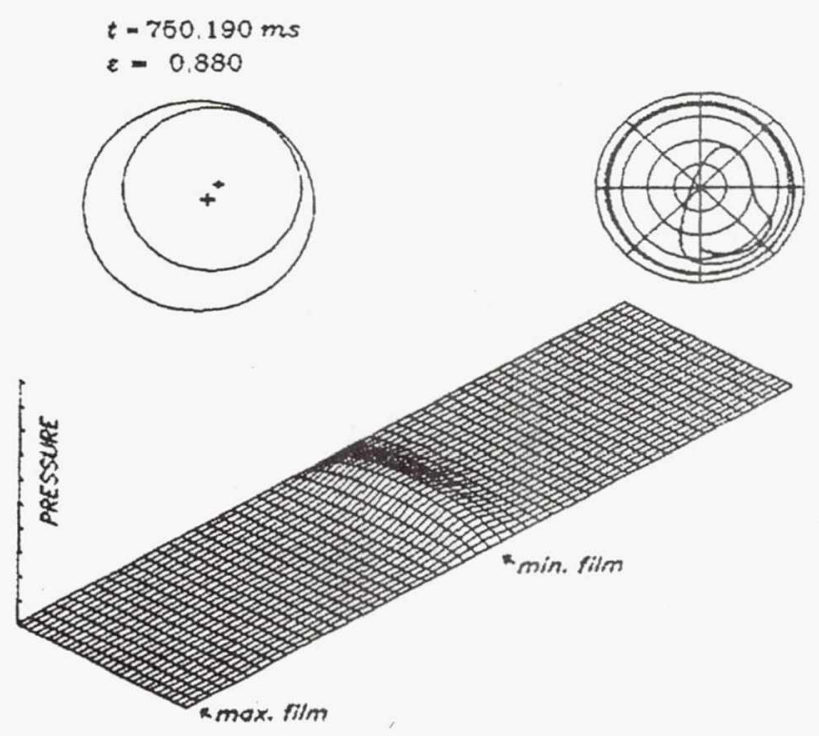

(iv) Zero applied load.

Figure 4b.-Pressure profiles - Reynolds B.C. $(\Omega=0.50)$. 


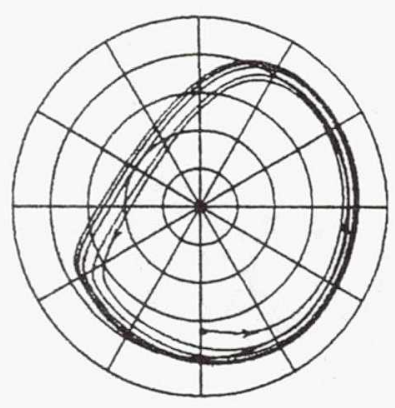

CAVITATION ALGORITHM

(a) Journal trajectory

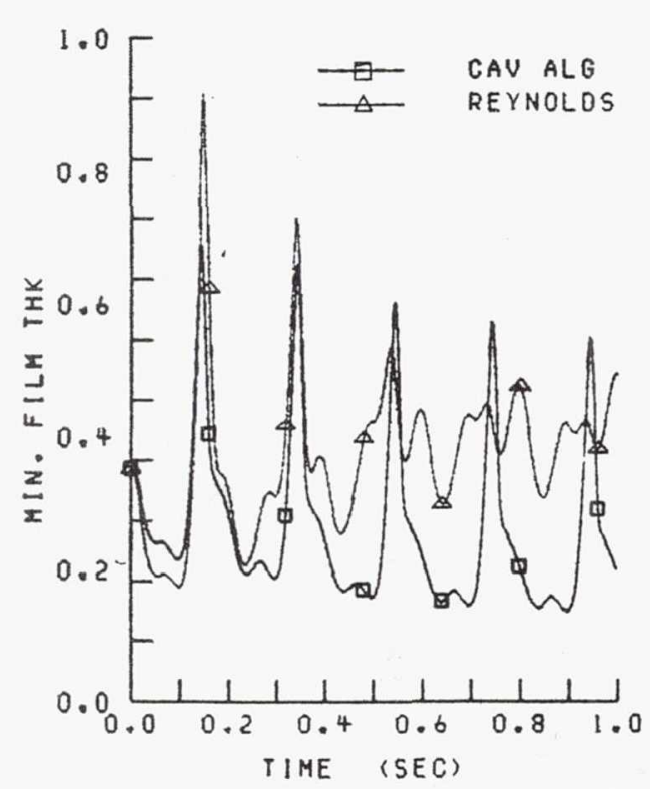

(b) Minimum film thickness.

Figure 5.-Periodic loading $(\Omega=1.0)$.
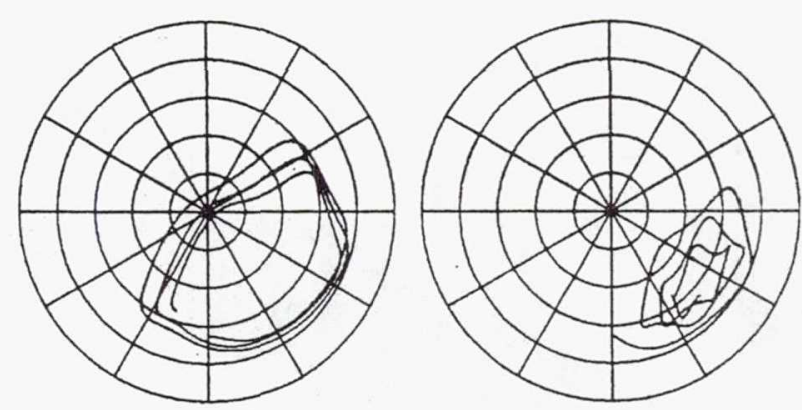

CAUITATION ALGORITHM

REYNOLOS B.C.

(a) Journal trajectory.

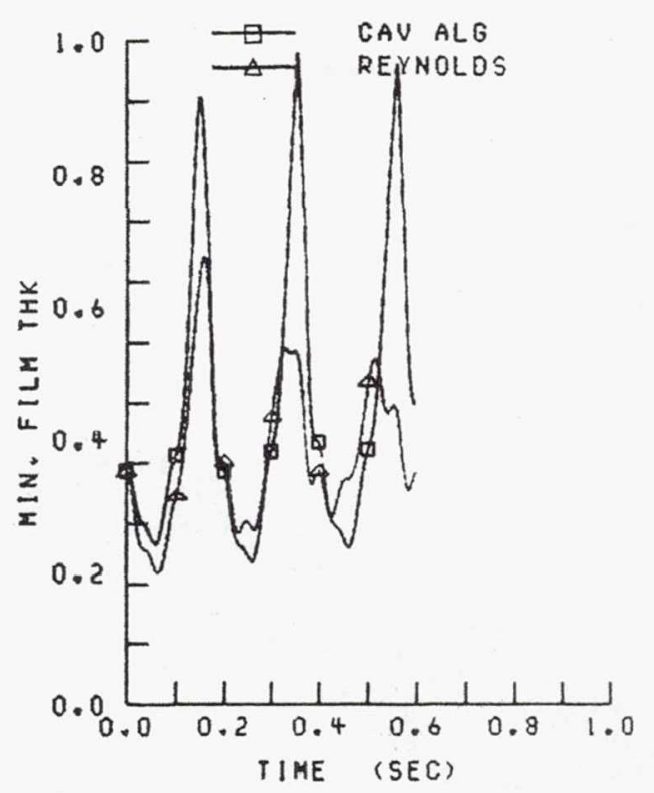

(b) Minimum film thickness.

Figure 6.-Periodic loading $(\Omega=2.0)$. 


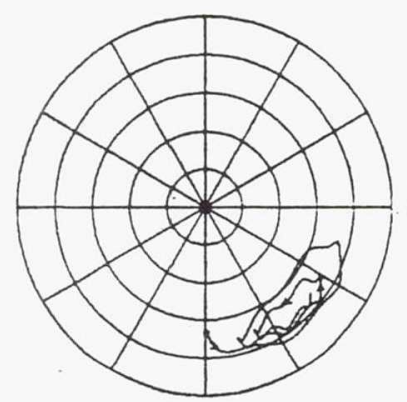

CAUITATION ALGORITHM

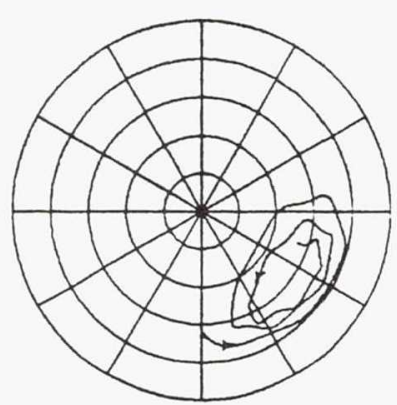

REYNOLDS B.C.

(a) Journal trajectory.

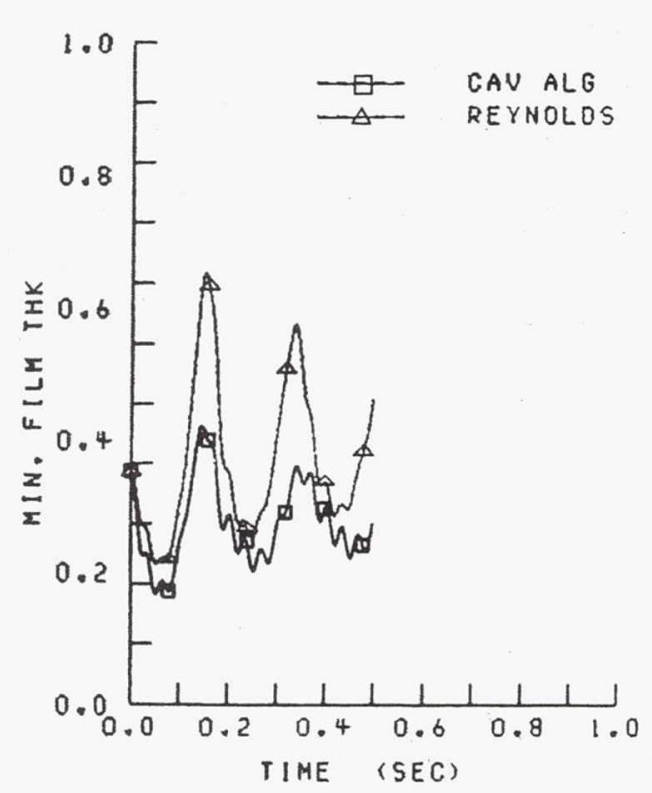

(b) Minimum film thickness.

Figure 7.-Periodic loading $(\Omega=3.0)$.
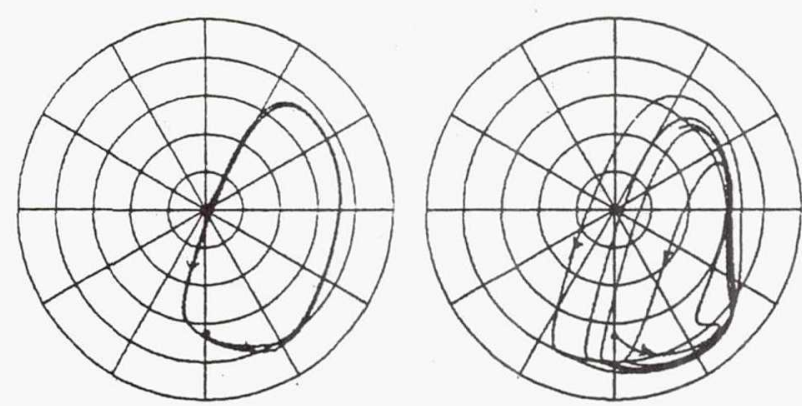

CAV. ALG. $(\bar{M}=0.5)$

CAV. ALG。 $(\bar{M}=2.5)$
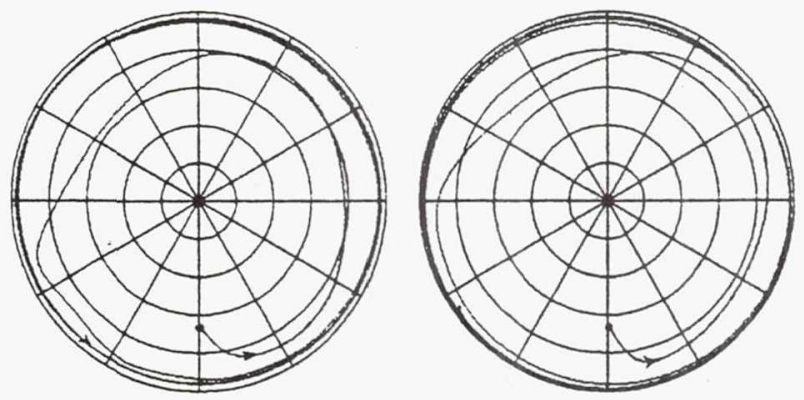

CAV. ALG, $(\bar{M}=10$.

CAV. ALG。 $(\bar{M}=25$,

Figure 8.-Effect of mass on journal trajectory $(\Omega=0.5)$. 

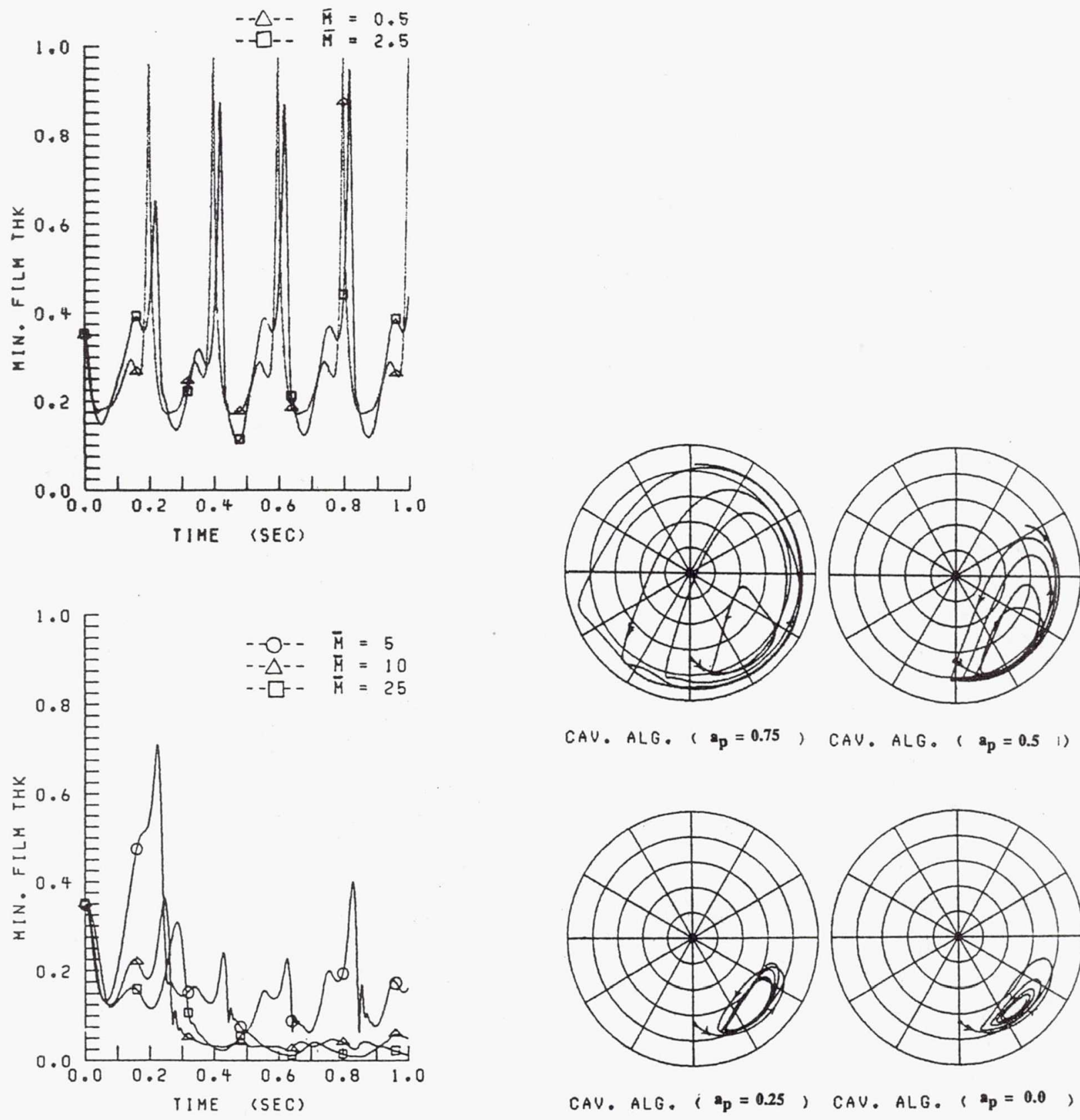

Figure 9.-Effect of mass on minimum film thickness $(\Omega=0.5)$.

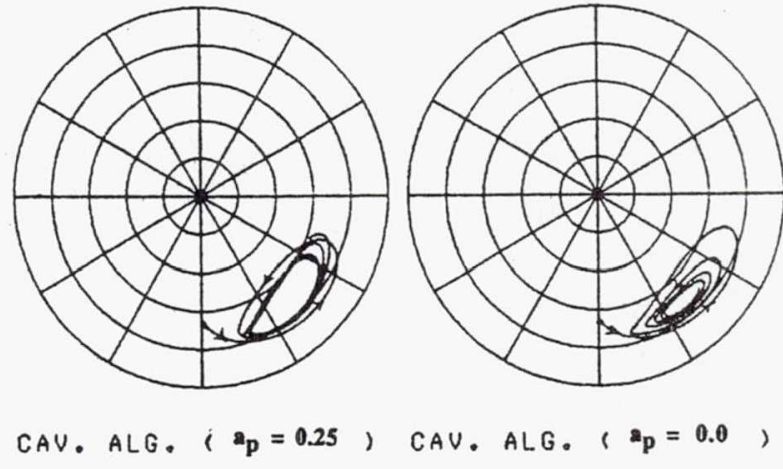

Figure 10.-Effect of amplitude of load variation on journal trajectory $(\Omega=0.5)$. 

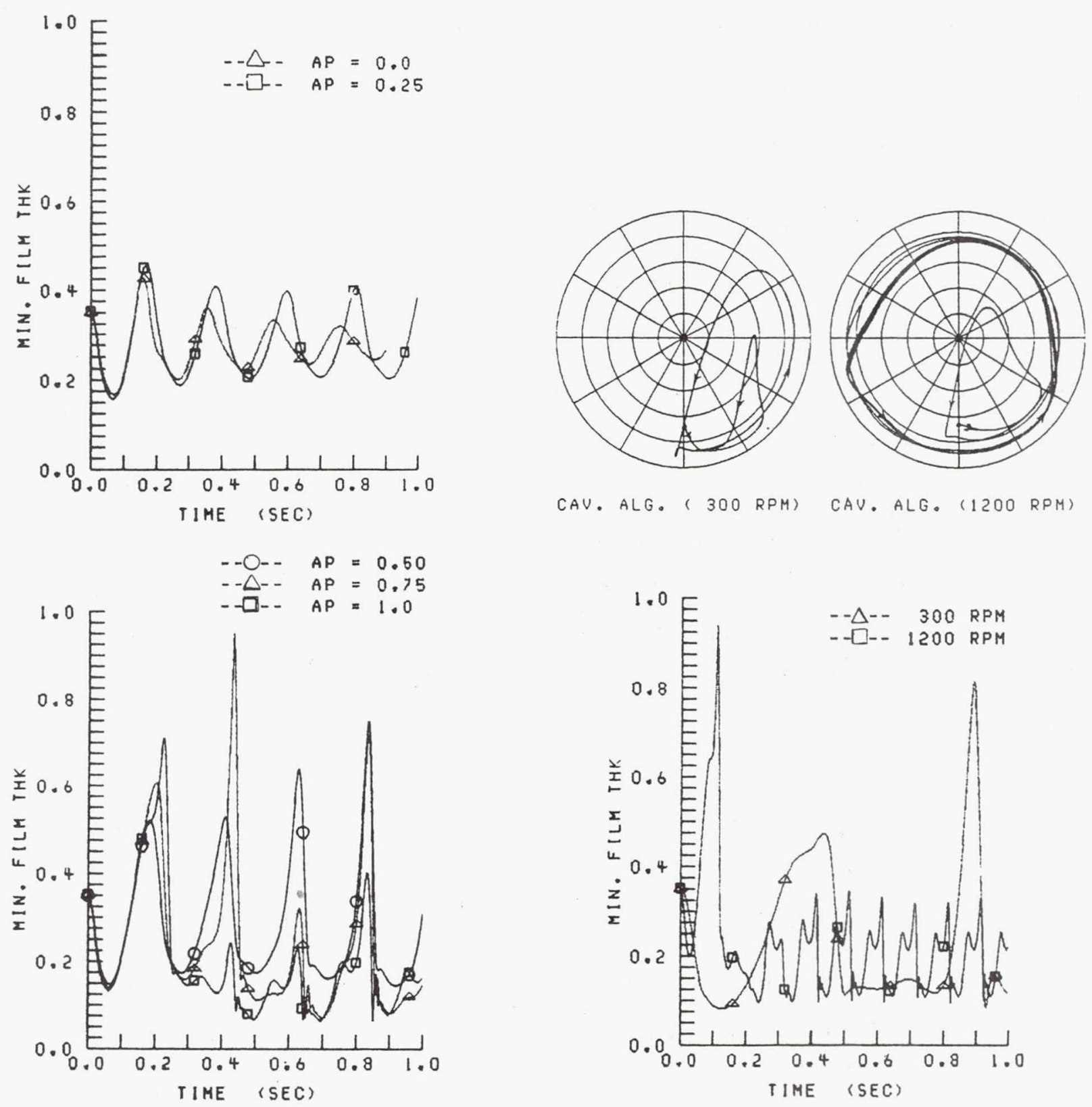

Figure 11.-Effect of amplitude of load variation on minimum film thickness $(\Omega=0.5)$.

Figure 12.-Effect of journal speed $(\Omega=0.5)$. 
Public reporting burden for this collection of information is estimated to average 1 hour per response, including the time for reviewing instructions, searching existing data sources, gathering and maintaining the data needed, and completing and reviewing the collection of information. Send comments regarding this burden estimate or any other aspect of this collection of information, including suggestions for reducing this burden, to Washington Headquarters Services, Directorate for information Operations and Reports, 1215 Jefferson Davis Highway, Suite 1204, Arlington, VA 22202-4302, and to the Office of Management and Budget, Paperwork Reduction Project (0704-0188), Washington, DC 20503.

\begin{tabular}{|l|r|r|}
\hline 1. AGENCY USE ONLY (Leave blank) & $\begin{array}{r}\text { 2. REPORT DATE } \\
1991\end{array}$ & $\begin{array}{r}\text { 3. REPORT TYPE AND DATES COVERED } \\
\text { Technical Memorandum }\end{array}$
\end{tabular}

4. TITLE AND SUBTITLE

Frequency Effects on the Stability of a Journal Bearing for Periodic Loading

6. AUTHOR(S)

D. Vijayaraghavan and D.E. Brewe
5. FUNDING NUMBERS

WU-505-63-5A

ILI61102AH45
7. PERFORMING ORGANIZATION NAME(S) AND ADDRESS(ES)

NASA Lewis Research Center

Cleveland, Ohio 44135-3191

and

Propulsion Directorate

U.S. Army Aviation Systems Command

Cleveland, Ohio 44135-3191

9. SPONSORING/MONITORING AGENCY NAMES(S) AND ADDRESS(ES)

National Aeronautics and Space Administration

Washington, D.C. 20546-0001

and

U.S. Army Aviation Systems Command

St. Louis, Mo. $63120-1798$
8. PERFORMING ORGANIZATION REPORT NUMBER

E-6242

11. SUPPLEMENTARY NOTES

Prepared for the STLE-ASME Joint Tribology Conference, St. Louis, Missouri, October 13-16, 1991.

D. Vijayaraghavan, National Research Council-NASA Research Associate at Lewis Research Center; D.E. Brewe, Propulsion Directorate, U.S. Army Aviation Systems Command. Responsible person, D.E. Brewe, (216) $433-6067$.

12a. DISTRIBUTION/AVAILABILITY STATEMENT

12b. DISTRIBUTION CODE

Unclassified - Unlimited

Subject Category 34

\section{ABSTRACT (Maximum 200 words)}

In this paper, stability of a journal bearing is numerically predicted when unidirectional periodic external load is applied. The analysis is performed using a cavitation algorithm, which mimics the JFO theory by accounting for the mass balance through the complete bearing. Hence, the history of the film is taken into consideration. The loading pattern is taken to be sinusoidal and the frequency of the load cycle is varied. The results are compared with the predictions using Reynolds boundary conditions for both film rupture and reformation. With such comparisons, the need for accurately predicting the cavitation regions for complex loading patterns is clearly demonstrated. For a particular frequency of loading, the effects of mass, amplitude of load variation and frequency of journal speed are also investigated. The journal trajectories, transient variations in fluid film forces, net surface velocity and minimum film thickness and pressure profiles are also presented.

\section{SUBJECT TERMS}

Journal bearing; Dynamic loading; Stability; Frequency effects; Periodic loading; Nonlinear motion; Cavitation

\begin{tabular}{|c|c|}
\hline $\begin{array}{l}\text { 17. SECURITY CLASSIFICATION } \\
\text { OF REPORT }\end{array}$ & $\begin{array}{c}\text { 18. SECURITY CLASSIFICATION } \\
\text { OF THIS PAGE } \\
\text { Unclassified }\end{array}$ \\
Unclassified
\end{tabular}

\section{SECURITY CLASSIFICATION OF ABSTRACT} Unclassified
NASA TM-105226

AVSCOM TR-91-C-040 
National Aeronautics and Space Administration

Lewis Research Center

Cleveland, Ohio 44135

Official Business

Penalty for Private Use $\$ 300$
FOURTH CLASS MAIL

ADDRESS CORRECTION REQUESTED 